\title{
\$sciendo
}

Ethics \& Bioethics (in Central Europe), 2018, 8 (1-2), 109-120

DOI:10.2478/ebce-2018-0002

\section{Access to medically assisted reproduction for legal persons: Possible?}

\author{
Hana Konečná ${ }^{1}$ \& Karolína Nováková ${ }^{2}$
}

\begin{abstract}
Along with the rapid growth that the field of assisted reproduction has experienced over the last few years, numerous ethical issues have arisen and need to be discussed thoroughly. One of them is the limitation of access to assisted reproduction techniques. Because no one should be discriminated against, it is essential to substantiate every single refusal of access carefully. The criterion of welfare of the child is used most frequently. In this paper, we propose a thought experiment aiming at contributing to the discussion by demonstrating that this criterion, even in its strictest form, can easily allow access to assisted reproduction for legal persons as well.
\end{abstract}

Keywords: assisted reproduction; legal aspects; access; legal person; welfare of the child; thought experiment

\section{Introduction}

There is a continuous discussion in the field of assisted reproduction surrounding whom should have access to medically assisted reproduction (MAR). Because no one should be discriminated against, it is essential to substantiate every single refusal of access carefully. Most recently, the topic was discussed in February 2018 in the Council of Europe in Strasbourg, on a two-day seminar entitled "Access and diversity of medically assisted reproduction in Europe", organized by the European Society of Human Reproduction and Embryology, together with the Council of Europe Bioethics Committee. The message of this event can best be summed up as follows: "What can be done? Recognize the existing need and follow it. Do not ignore the current world. Be inclusive, not exclusive. Concentrate on how, not on who. Make it safe, efficient and fair for those in need of help" (Rautakallio-Hokkanen, 2018).

MAR has become a method of becoming parents for an increasing number of people. Moreover, the possibility of extracorporeal manipulation with oocytes and embryos has significantly broadened the alternatives of how to become parents over the last few decades. Therefore, MAR can essentially make parents of anyone. The important question, however, is not "how" but "who" i.e., should there be any regulations defining access to MAR? And, if so, who should define them and to whom should they apply? Currently, a criterion of welfare of the child is used most frequently. In this paper, we want to demonstrate that the criterion of welfare of the child, even in its strictest form, easily allows access to MAR for legal persons as well.

Over the last few years, there have been a number of such debates, including The welfare of the child, published by Blyth and Cameron (1998) and continued by Pennings (1999); The Pre-congress course 8 SIG Psychology and Counselling entitled Theory and practice update in third party reproduction at the ESHRE meeting in Stockholm (2011); and Pre-congress course 5 SIG Ethics and Law titled Non-standard requests? Ethical and legal aspects of medically assisted reproduction in singles, lesbian and gay couples, and transsexuals at the ESHRE meeting in Istanbul (2012).

Moreover, the welfare of the child criterion was pronounced to be insufficient in Human Reproduction (Blyth \& Cameron, 1998). Although efforts have been made to open a

\footnotetext{
${ }^{1}$ University of South Bohemia in České Budějovice (Czech Republic); email: hkonecna@zsf.jcu.cz

${ }^{2}$ Masaryk University (Czech Republic); email: novak.karo@gmail.com
} 
discussion to re-evaluate the welfare of the child principle (Solberg, 2008), it is still used as a general criterion to determine access to MAR, recommended by both the European Society of Human Reproduction and Embryology (ESHRE) and the American Society of Reproductive Medicine (ASRM).

\section{Welfare of the child in various documents}

Most governments of western countries have accepted that MAR is a matter of public policy. Therefore, an interplay between the state, professionals and parents arises (Smajdor, 2015; Daniels et al., 2000). In the legislature of some countries, the welfare of the child criterion is used to regulate access to MAR. In the following paragraphs, we refer to some concrete examples.

In Australia, the Assisted Reproductive Treatment Act (2008) states that "the welfare and interests of persons born or to be born as a result of treatment procedures are paramount". Similarly, the New Zealand's Human Assisted Reproductive Technology Act (2004) quotes that "the resultant child should be an important consideration". In the United Kingdom, the Human Fertilisation and Embryology Act (2008) requires clinics to take into account the welfare of the child when providing fertility treatment. Interestingly, the welfare of the child requirement replaced the "need for a father" requirement that was part of the previous 1990 version of the Act. Extensive research evaluating regulations of MAR written into law has recently been carried out in the UK (Blyth, Burr \& Farrand, 2008; Gurnham \& Miola, 2012; Lee, Macvarish \& Sheldon, 2014; Sheldon, Lee, \& Macvarish, 2015). The Canadian Assisted Human Reproduction Act (2004) is also built on the welfare of the child: it states that "the health and well-being of children born through the application of assisted human reproductive technologies must be given priority in all decisions respecting their use".

Another important document, The Council of Europe Report on Human Artificial Procreation (1989), states that "the techniques of artificial human procreation may...be used for the benefit of a heterosexual couple when appropriate conditions exist for ensuring the well-being of the future child".

\section{Efforts to define the welfare of the child}

There are various approaches to normative ethics. Normative ethical theories may generally be divided into two schools: deontological and utilitarian theories (Gaus, 2001). On one side, deontological ethics - or deontology - represents a normative ethical position that judges the morality of an action based on the action's adherence to a rule or rules. Within deontological reasoning, consequences may play a subordinate part but they are never the deciding factors in determining the rightness of the act or decision (Pennings, 2011). Deontological ethics is commonly contrasted to consequentialism, utilitarianism, and pragmatic ethics. These positions derive the correctness or incorrectness of actions from their consequences (Hursthouse, 2013). Welfare of the child is a consequentialist principle. In this paper, we want to note that a pure consequentialist position towards welfare of the child is not sufficient because it does not exclude "non-natural" persons from reproduction.

According to Lee and Morgan, welfare is a broad notion comprising both material and psycho-social well-being; however, it is widely accepted that the most important aspects of a child's welfare are those that pertain to "stability and security, the loving and understanding care and guidance, the warmth and compassionate relationships that are the essential for the full development of the child's own character, personality and talents" (Lee \& Morgan, 2001).

Several studies aiming to define criteria determining the welfare of the child have been carried out recently. A Swiss team of MAR professionals conducted a study exploring attitudes of paediatricians, gynaecologists and experienced parents towards the welfare of children to be conceived using assisted reproduction (De Geyter, Boehler \& Reiter-Thei, 
2010). Their study ranked the following 13 hypothetical criteria that could determine welfare of a future child: avoidance of future harm to the child, absence of mental illness in both partners, limited paternal age for reproduction, future provision of education for the child, both parents' life expectancy, stable relationship between both partners, good prognosis of normal health of the child, willingness to integrate socially, good quality of the couple's relationship, shared home for both partners and their child, sufficient social network of both parents, adequate housing conditions, and adequate social and financial living conditions. Another recent study (De Lacey, Peterson \& McMillan, 2015) focused on how welfare principles play out in counselling practice. The authors reported that not only can the welfare of a child be a meaningful concept to counsellors in the field of MAR but also that it can be impractical due to a lack of clarity.

Underlying the current ethical debate on the welfare of the child is the widely held belief that it is almost always in the child's best interests to be born, save for exceptionally rare instances when the child would be exposed to a life that is "not worth living" (Blyth, 2008; Larcher, 2007; Harris, 2004). However, this belief is not shared without reservations. One of the possible present answers to the question of quality of life, represented by David Benatar, is that life has no quality, so it is better not to be at all. That is why he recommends that those children should not be born at all, because we would only bring them misery (Benatar, 2013).

Most countries agree that the welfare of resulting offspring ought to be considered. Furthermore, according to Robertson (1994), procreative liberty, as with all other human rights, is not absolute and may be curtailed when the potential of substantial harm can be established. This line of thought begs several questions, the most obvious being how to define substantial harm and the second being what level of proof is required.

The European Society of Human Reproduction and Embryology (ESHRE), the world's most influential professional organization (it organized, for example, a workshop to promote access to MAR, in the Council of Europe in February 2018), also selected the welfare of the child to be the main criterion in medically assisted reproduction (Pennings et al., 2007). The first part of the paper addressed the risks associated with would-be parent(s), while the second part focused on possible risks inherent in the technologies and treatments themselves. The authors proposed factors that need to be evaluated while weighing the risk factors for a child; these are, among others, medical conditions of the would-be parent(s), substance abuse, child abuse, violence in the family, addiction, mental retardation, psychiatric disorders, and poverty, among others. Consequently, the authors distinguish three different standards: (1) the maximal welfare, according to which no medical assistance should be provided when there are indications that the life conditions of the future child will not be optimal; (2) the minimum threshold, according to which medical assistance to reproduction is only unacceptable if the quality of life of the future child is so low that it would have been better off not to have been born; and (3) reasonable welfare, according to which assistance is acceptable if the future child will have the abilities and opportunities to realize those dimensions and goals that make a human life valuable. When the predicted level of well-being of the future child is estimated to fall below the standard of reasonable welfare (i.e., when there is a high risk of serious harm), the physician has an obligation to refuse participation. Based on these criteria, the authors propose that the fertility specialist should refuse to collaborate in the parental project of would-be parents if he or she judges that there is a high risk of serious harm to the future child.

Pennings (1999, p. 1146) explains these three principles in more detail:

- "The maximum welfare principle implies that one should not knowingly and intentionally bring a child into the world in less than ideal circumstances". Accordingly to an appeal by Lancet's editors (1993), Pennings (1999) proposes that the long-term well-being of the child should be of overriding importance: "of course, 
many fertile couples have unplanned conceptions and some of their babies are born into circumstances that are far from ideal; we have little control over such 'natural' events. However, ethical considerations inevitably enter into the decision to use high technology to give a woman a pregnancy". He notes that children need a stable home with mature caring adults who themselves have a sound relationship. Finally, he proposes that because we can control (at least to a certain extent) the circumstances in which a child is made if the candidates are infertile, we ought to restrict our cooperation to those cases which maximize the welfare of the child. This fact explains why the standard for medically assisted procreation must and should be higher than for natural reproduction: "Taking the maximum welfare principal as a measure, a bias against some groups of want-to-be-parents arises. Strictly taken, this standard would exclude the overwhelming majority of the population from procreation. Should people who are poor, unemployed, handicapped, obese, workaholics and/or old all be rejected as potential parents since the child they will have would have had a better life had it been born to other parents?" (Pennings, 1999, p. 1147).

- The minimum threshold principle is connected to a weak interpretation of the right to procreate: "a person has a right to rear children if he meets certain minimal standards of child rearing" (Pennings, 1999, p. 1147). This standard does not compare the welfare of the child-to-be-created with other possible children but only verifies whether the quality of life of the future child is above the minimum threshold. One of the most frequently used minimum thresholds can be called "wrongful life" or the "worse than death" standard: "A child should not be brought into the world if and only if it would have been better never to have been born at all" (Pennings, 1999, p. 1148). The minimal threshold standard attributes a disproportionate importance to the autonomy principle as expressed in the right to procreate of the parents at the expense of the welfare of the child.

- According to the reasonable welfare principle, the principle employed to evaluate the applications of new reproductive technologies could be stated as follows: "The provision of medical assistance in procreation is acceptable when the child born as a result of the treatment will have a reasonably happy life" (Pennings, 1999, p. 1148). Because it is rather difficult to give an elaborative description of which construction constitutes the normal state of welfare, we have to rely to a considerable extent on our common sense. The author suggests that "an individual has a decent welfare level when he has the abilities and opportunities to realize those dimensions and goals that in general make human lives valuable" (Pennings, 1999, p. 1148).

Pennings concludes that

"once we discard the maximum welfare principle and adopt the reasonable well-being standard, as we do for the evaluation of parental responsibility in other instances, there are no indications that the technology is getting out of hand. Still, some extreme (even if rare) instances (as very old mothers, some examples of posthumous reproduction) do request continued vigilance. The renewed attention for the welfare of the child can serve as a counterweight against the overextended autonomy of the parent(s) in those situations" (Pennings, 1999, p. 1150).

Generally, there are two major concerns: first, there are no reliable predictive criteria for inadequate parenting and, thus, no criteria that can be used to guarantee the best interests of the child (Harris, 1990); second, a choice of the principle to interpret the level or measure of welfare is often problematic (Pennings, 1999).

According to Mumford, Corrigan and Hull, the core question that needs to be debated is whether or not assistance should be given to bring a child into being. The authors argue that procreation is never a question only of individual personal rights, and say that it always 
requires at least two participants (Mumford, Corrigan \& Hull, 1998). There can be no "right" to something, which necessarily involves a second party who has an equal right to withhold co-operation. Blyth and Cameron emphasized the lack of any instrument measuring the welfare of the child (Blyth \& Cameron, 1998). They argue that even though the value of this type of test would be widely accepted, it may be fraught with difficulty in practice. Up to now, to our knowledge, no such instrument has been developed that would be generally accepted and widely spread. Moreover (and from our point of view, more importantly), they express serious doubts about using the welfare of the child as the only sufficient criterion for discussing access to MAR.

We, the authors, agree with the doubts of Blyth and Cameron that the welfare of the child criterion may not be sufficient. We believe resignation is driving the current commitment to the welfare of the child and instead promote further research into the existence of additional criteria. Our concerns are even greater that those of Blyth and Cameron; they will be the subject of the present paper (Blyth \& Cameron, 1998).

\section{Methodology}

We will try to demonstrate the essence of our concerns by a thought experiment in which we will try to the answer the question whether the application of the welfare of the child criterion is sufficient to preclude access to MAR to legal persons. The scenario (an imaginary situation) would unfold as follows:

One or more natural persons establish a foundation that aims to give an opportunity for life to "forgotten" or - maybe more truthfully - unwanted embryos in the freezers of a regional centre for assisted reproduction. In such a case, the reason for parenthood would clearly be purely altruistic. They intend to find young, healthy, heterosexual, married couples with a strong pro-parenting orientation. These couples would become the surrogate parents of children born from unwanted embryos (the husband of the mother would be the surrogate father of the child). Parental rights adhere to the foundation; in some countries (e.g., Russia, India, Greece) the foundation is immediately legally recognized to be the parent after the birth of the child as an "applicant" for surrogate parenthood. (An organization as the bearer of parental rights is not unusual. For example, in foster care or institutional care, parental rights are withdrawn from biological parents and transferred to a governmental institution to protect the child). Surrogate parents would then become foster parents, employees of the foundation. The foundation would pay them foster reimbursements that would be higher and given for a longer duration than usually provided (foster reimbursements are typically at low rates and only paid until the child reaches the age of majority) to provide sufficient resources for proper childcare. It may be logical to ask why the foundation does not leave parental rights to the surrogate parents. We argue that:

1. In regular families, governmental compensation for childbearing is minimal; therefore, many parents are forced to work and leave their young children in the care of others. Moreover, the time of childcare is almost not recognized in the calculation of pension entitlements. In our scenario, caregivers are not endangered in this way - both the time of providing childcare and the financial allowance are parameters of their employment.

2. The foundation wants to keep the option to intervene in a family should a crisis develop: within the foundation, there is an advisory board, whose members are experts in the areas of developmental psychology and paediatrics, and also include representatives of the foster parents employed by the foundation. This advisory board resolves any crises should they arise.

The foundation would also provide housing for families. Each foster family would live separately in different places (it would not be an alternative to SOS villages). The foundation would support the healthy development of the child in the best possible way; it would provide 
financial support for education, extracurricular activities, etc. When the children reach adulthood, the foundation would provide them with a good start to their independent lives; it would help with covering the costs of their first apartment and financial resources for living expenses, as is common in other families. If the foundation ceased to exist, it would be possible for the children under its care to inherit its wealth.

We will seek the arguments in favour of or against the access of a legal person to MAR in studies discussing such access of other non-standard groups.

\section{Discussion}

Experts agree that defining the characteristics that would specify the welfare of the child is difficult, if not impossible. As Pennings emphasizes, "we have to rely to a considerable extent on our common sense" (Pennings, 1999, p. 1148). As mentioned above, ESHRE (Pennings et al., 2007) describes in, its task force, possible risks for a child in two different aspects: (1) risks associated with the would-be parent(s); and (2) risks inherent in the technologies and treatments themselves. Stern et al. (2003) categorise risks to those related to patient attributes (i.e., marital status, age, sexual preference); and those related to patient behaviours (i.e., substance abuse, psychiatric history, child abuse).

For the purpose of this paper, we create an intersection of these categories and extend them further. Risk factors associated with technology are not included in the scope of this paper.

We propose the categorization of risks as follows:

1. would-be parent(s) attributes - health status, age, sexual preference, marital status, individual characteristics relating to parenting, financial situation, etc.

2. would-be parent(s) behaviours - substance abuse, potential child abuse, etc.

Some may argue that, due to a lack of donated gametes, an additional criterion should be the number of children would-be parents already have. Nevertheless, this criterion is not relevant for our thought experiment because there is an abundance of frozen embryos. By contrast, problems actually arise with what to do with them (e.g., a current Belgian law allows access to MAR only after partners decide what they will do with redundant embryos and does not allow them start new treatment unless they use all of their frozen embryos).

Across the body of relevant literature, we can identify various arguments for providing and/or restricting access to MAR to different groups. The following criteria are most frequently used when discussing access to MAR for post-menopausal women: duration of natural reproductive life; parental capacity; the success of IVF medical risks; psychological risks (Goold, 2005; Landau, 2004; Pennings, 1995; 2001).

\section{Restrictions based on resource allocation}

Most countries offering MAR apply health care rationing as a standard model. Many centres providing MAR are not able to assist all of those who seek their help. Public funding is either non-existent or very limited, and there may also be a shortage of gamete donors. Therefore, it is common that centres exclude those applicants who already have children. It is also common for publicly funded centres to restrict access to MAR by setting an age limit for females seeking IVF. According to Mumford and Corrigan, this refusal could be seen as providing services to those with the greatest need, which is consistent with a policy of providing treatment first where it has the highest likelihood of success (Mumford \& Corrigan, 1998). According to ESHRE, the following ethical principles are of utmost relevance when considering access to MAR: respect for autonomy, beneficence and non-maleficence, justice, and the welfare of the child. There is no sound reason to dismiss access in these situations; such categorical dismissal would imply discrimination (De Wert et al., 2014).

We consider it worth mentioning that even though the question of gender has been dominating the relevant literature over the past decades, it has not exclusively been proven 
that the desire for parenthood and parental skills differ significantly between women and men. Although surrogate motherhood is usually legal in those countries that are most active in discussions about access to MAR, gay couples and single men are not usually referred to as non-standard request groups. Even though non-standard requests for MAR are varying, several non-standard groups of applicants may be identified. These include for example:

\section{Homosexual couples}

A non-standard group that has been studied a lot in the context of access to MAR is homosexual couples. According to Fasouliotis and Schenker (1999) as well as Grover et al. (2013), not only law and custom but also subjective intention can define "family". Using this method of determination, a homosexual couple in a stable relationship and caring for a child or children together function as a "family".

According to Peterson (2005), the claim of non-qualification due to absence of medical infertility is routinely used as a reason to deny MAR services to lesbians. However, because both members of a lesbian couple cannot biologically produce sperm, they could be considered to be technically infertile and thus qualify for access to donor sperm in the same manner as a heterosexual couple in which the male partner is unable to produce enough healthy sperm to achieve conception naturally (Pearn, 1997). Furthermore, Stuhmcke (1997) argues that although it is possible for lesbians to obtain private sperm donation and self-inseminate, the potential health risks combined with the possibility of future demands for paternal involvement in child-bearing decisions or access make anonymous donation via MAR services preferable.

Generally, there are two common assumptions about children raised in homosexual families. First, there is an assumption that they will be teased, ostracized or bullied at school and, as a result of this abuse, they will develop psychological problems. Secondly, some authors are concerned about these children's gender identity formation - they assume that girls will be less feminine and boys less masculine compared to those raised by heterosexual couples. Furthermore, some believe that they will grow up to be lesbian or gay themselves. According to our research, no studies have proven any significant differences between children of lesbian couples and single heterosexual mothers in terms of emotional well-being, quality of friendships, self-esteem, or expression of masculinity or femininity. According to Golombok (1998), the most significant finding emerging so far from the studies of lesbian families with a child conceived by donor insemination is that co-mothers in two-parent lesbian families are more involved with their children than are fathers in two-parent heterosexual families. Based on these findings, it is clear that the welfare of the child depends greatly upon the quality of the arrangements made between the adult parties involved (Brewaeys, 1998).

Recently, another ethical issue related to homosexual couples requesting MAR has arisen with Reception of Oocytes from Partners (ROPA). With this alternative procedure, lesbian women are allowed to share biological motherhood - the gestational mother receives an egg from her partner who then becomes the genetic mother. While some authors argue about its ethical acceptability, Zeiler and Malmquist (2014) argue that ROPA is not more ethically problematic than other cases of non-standard requests for MAR. Furthermore, they propose that ROPA actually gives rise to even fewer ethical questions than some procedures used in current medical trials (e.g., live uterus transplantation). Dondorp (2012) notes the analogy of ROPA to Intracytoplasmic Sperm Injection (ICSI), which allows heterosexual couples with male infertility to have "a child together" when they could also have a child through donor insemination. Dondorp (2012) concludes that the fact that some lesbian couples request ROPA urges us to rethink the aims of MAR: "Is it to help the 
infertile (or the childless) to have a child? Or is it to help couples to have children together?"

Another specific example is the experiences of gay couples. Like single men, gay couples need to engage a surrogate mother while pursuing parenthood. Very little data are available about the numbers of requests to-date by gay couples, but generally, such requests are less frequent than requests from lesbian couples (De Wert et al., 2014).

\section{Single heterosexual mothers}

Even though single heterosexual women applying for MAR may seem to be the "classic case", becoming a single mother was not the first choice for many of these women (Graham \& Braverman, 2012). They simply had not yet found the right partner. The most common argument for restricting access of single women to MAR is the assumption that children in single-parent families do less well than those in two-parent households, arguing that their psychological adjustment and academic achievements are worse. In addition, they are more likely to suffer economic hardship (McLanahan \& Sandefur, 1996).

One question that is often posed regarding single-mother families is whether the negative consequences for children who are raised by a single mother result from the absence of a father or from the absence of a second parent from the home in general, whether female or male. Golombok (1998) concludes that it appears to be the latter - the role of an additional parent and not the role of a male parent in particular is beneficial to the child. According to her research, family circumstances appear to be the best predictor of outcomes for children in single-mother homes. Golombok (1998) also states that "the true determining factors for the child's well-being (strong desire for parenthood, warm and supportive relationships, etc.) do not coincide with and are not determined by the sexual orientation, the number of parents or the genetic relatedness".

Another specific case within the non-standard group is post-menopausal women. According to research, the average success rate of live births per cycle of IVF is only 2.5 $\%$ in women older than 45 years. The argument against postmenopausal childbearing is based on the belief that pregnancy in older women goes "against nature". However, according to Peterson (2005), this belief ignores the fact that, at present, it is socially and medically acceptable to create a temporary or permanent "against nature" infertile state in young women with the use of contraceptives or surgery. On the other hand, some authors (Sobotka, 2010) suggest that the "social advantage" of late parenthood may outweigh the biological advantage of early parenthood, as older parents are more experienced and knowledgeable, are better off economically, face lower risk of divorce, and can more easily afford childcare.

\section{Transsexual people}

According to ESHRE (De Wert et al., 2014), applications for MAR by transsexual people, and in particular couples comprising of at least one transsexual person, are currently rare although steadily increasing. Reproductive options are diverse; they include IVF with donor sperm in cases when transsexual males (female-to-male transsexuals) have a female partner and use of a surrogate mother when transsexual women (male-to-female transsexuals) have a male partner. Another consideration is that fertility preservation may be a way to help transsexuals have genetically related offspring in the future.

\section{HIV discordant couples}

Spriggs \& Charles published a paper evaluating arguments for and against offering MAR specifically IVF - to HIV discordant couples. They argue that if treatment is denied, there is an increased risk of disease transmission from unprotected sex. They conclude that 
offering MAR to such couples is likely to produce more benefit than harm and violates no ethical principles (Spriggs \& Charles, 2003).

\section{Is the legal person status of an MAR applicant a risk for the welfare of the child?}

Spriggs \& Charles (2003) note that couples that can have children without reproductive assistance are not scrutinised in the same way as those that are infertile. We agree but would note that the responsibility of an individual and a couple to the child is very different from that of an organization. Additionally, as the authors correctly highlight, we neither have a reliable way of predicting who will or will not be a good parent nor have an agreed-upon measure of what constitutes a good parent. Nevertheless, given the issue is much broader, we try to evaluate whether an institution should or could adopt responsibility for MAR procedure and why. Naturally, the decision-making of the institution must have different criteria than the decision-making of an individual or a couple.

In jurisprudence, a natural person is a real human being in contrast to a legal person, which is defined as an organization, either private (e.g., business entity) or public (e.g., government). Legal persons (lat. persona juris) are of two types: natural persons - people - and juridical persons (also called juristic or artificial or fictitious persons, lat. persona ficta) - groups of people, such as corporations. In many cases, fundamental human rights, including reproduction, are granted to natural persons only (Martin, 2003).

Even though it may seem absurd, it is important - regarding our topic - to realize one fundamental consideration: a legal person cannot have children because it is not a human being.

Surrogate motherhood is accepted even though donor gametes are used. As stated in the ESHRE Task force 10 (Shenfield et al., 2005, p. 2707): "Surrogacy is a morally acceptable method of assisted reproduction of last resort... The wish of the child to know its genetic origin should be taken into consideration by the parents in cases where donor gametes or the oocyte of the surrogate have been used". The future parents are actually not physically part of the process at all; they are only taking the role of juridical persons. With that, what is the difference from the legal persons? Let's take posthumous reproduction as an example. According to ESHRE Task force 11 from 2006, posthumous reproduction in the context of the initial parental project is acceptable. At the same time, lawyers argue that an individual gains legal personhood when they are born and loses it when they die. A dead person is not a legal person anymore, contrary to the definition of a judicial person. Thus, how can a dead person have access to MAR?

A legal person as defined above is not a human and does not produce gametes, but this is not an obstacle in other non-standard request cases. As Pearn notes: "Neither member of a lesbian couple can produce sperm, they could be considered to be technically infertile and thus qualify to access donor sperm in the same manner as a heterosexual couple in which the male partner is unable to produce enough healthy sperm to achieve conception naturally" (Pearn, 1997, p. 319).

\section{Conclusion}

We hope it has been demonstrated that if we take the consequentialist ethical perspective only regulating access to MAR by the criterion of the welfare of the child - there are no substantive arguments for excluding legal persons from having access to MAR. Furthermore, we argue that use of this criterion makes the decision of access to MAR more complex and therefore more difficult. As far as we are concerned, it is necessary to embrace another deontological criterion that could be accepted by everyone, regardless their values and ethnicity. Our article is provocative; perhaps our argumentation is not indisputable in all 
points. However, the article was written with the intention of provoking a debate, not to push a legal person to MAR.

Current legal regulation theoretically enables legal persons to apply for MAR. Is this the answer to the quotes quoted in the introduction to this article ("What can be done? Recognize the existing need and follow it. Do not ignore the current world. Be inclusive, not exclusive. Concentrate on how, not on who. Make it safe, efficient and fair for those in need of help".)? Will FC Sparta Prague or FC Spartak Trnava take their own live mascot? Manchester United, we think this option already exists.

\section{Acknowledgement}

This article was supported by the project GA ČR no. 17-07753S (Czech Science Foundation) "Surrogacy in the CR: legal, psychosocial and ethical analysis".

\section{References}

ASSISTED HUMAN REPRODUCTION ACT (S.C. 2004, c. 2), [online] [Retrieved February 2, 2018]. Available at: http://laws-lois.justice.gc.ca/eng/acts/A-13.4/page-1.html.

ASSISTED REPRODUCTIVE TREATMENT ACT NO. 76 OF 2008, [online] [Retrieved February 2, 2018]. Available at: http://www.legislation.vic.gov.au/Domino/Web_Notes /LDMS/PubStatbook.nsf/f932b66241ecf1b7ca256e92000e23be/3ADFC9FBA2C0F526CA25 751C0020E494/\$FILE/08-076a.pdf.

BENATAR, D. (2013): Nebýt či být: O utrpení, které přináší příchod na tento svět [Better Never to Have Been: The Harm of Coming into Existence], trans. D. Micka. Prague: Dybbuk. BLYTH, E. (2008): To Be or not to Be? A Critical Appraisal of the Welfare of Children Conceived through New Reproductive Technologies. In: International Journal of Children's Rights, 16(4), pp. 505-522.

BLYTH, E., BURR, V. \& FARRAND, A. (2008): Welfare of the child assessments in assisted conception: A social constructionist perspective. In: Journal of Reproductive and Infant Psychology, 26(1), pp. 31-43.

BLYTH, E. \& CAMERON, C. (1998): The welfare of the child. In: Human Reproduction, 13(9), pp. 2339-2355.

BREWAEYS, A., PONJAERT, I., VAN HALL, E., \& GOLOMBOK, S. (1997): Donor insemination: child development and family functioning in lesbian mother families. In: Human Reproduction, 12(6), pp. 1349-1359.

DANIELS, K. R., BLYTH, E., HALL, D., HANSON, K. M. (2000): The Best Interests of the Child in Assisted Human Reproduction: The Interplay between the State, Professionals, and Parents. In: Politics and the Life Sciences, 19(1), pp. 33-44.

DE GEYTER, CH., BOEHLER, B., \& REITER-THEIL, S. (2010): Differences and similarities in the attitudes of paediatricians, gynaecologists and experienced parents to criteria delineating potential risks for the welfare of children to be conceived with assisted reproduction. In: Swiss Medical Weekly, 140: w13064, [online] [Retrieved February 2, 2018]. Available at: http://www.smw.ch/content/smw-2010-13064/.

DE LACEY, S. L., PETERSON, K., \& MC MILLAN, J. (2015): Child interests in assisted reproductive technology: How is the welfare principle applied in practice? In: Human Reproduction, 30(3), pp. 616-624.

DE WERT, G., DOLNDORP, W., SHENFIELD, F., BARRI, P., DEVROPEY, P., DIEDRICH, K., TARLATZIS, B., PROVOOST, V., \& PENNINGS, G. (2014): ESHRE Task Force on Ethics and Law 23: Medically assisted reproduction in singles, lesbian and gay couples, and transsexual people. In: Human Reproduction, 29(9), pp. 1859-1865. 
DONDORP, W. (2012): Lesbian couples sharing biological motherhood: IVF for reproductively healthy women? 28th Annual Meeting of ESHRE in Istanbul, Turkey, from 1 to 4 July 2012.

EUROPEAN PARLIAMENT (2009): Human Enhancement Study, IP/A/STOA/FWC/200528/SC35, 41 \& 45, [online] [Retrieved February 2, 2018]. Available at: http://www.europarl.europa.eu/RegData/etudes/etudes/join/2009/417483/IPOL-JOIN_ET(20 09)417483_EN.pdf.

FASOULIOTIS, S. \& SCHENKER, J. G. (1999): Social aspects in assisted reproduction. In: Human Reproduction Update, 5(1), pp. 26-39.

GAUS, G. F. (2001): What is deontology? Part one: orthodox views. In: Journal of Value Inquiry, 35(1), pp. 27-42.

GOLOMBOK, S. (1998): New families, old values: considerations regarding the welfare of the child. In: Human Reproduction, 13(9), pp. 2339-2355.

GOOLD, I. (2005): Should older and postmenopausal women have access to assisted reproductive technology? In: Monash Bioethics Review, 24(1), pp. 27-46.

GROVER, S. A., SHMORGUNA, Z., MOSKOVTSEVA, S. I., BARATZA, A., \& LIBRACH, C. L. (2013): Assisted reproduction in a cohort of same-sex male couples and single men. In: Reproductive BioMedicine Online, 27(2), pp. 217-221.

GRAHAM, S. \& BRAVERMAN, A. (2012): ARTs and the Single Parent. In: M. Richards, G. Pennings \& J. Appleby (eds.): Reproductive Donation. Cambridge: Cambridge University Press, pp. 189-210.

GURNHAM, D. \& MIOLA, J. (2012): Reproduction, Rights, and the Welfare Interests of Children: The Times They Aren't A-Changin'. In: King's Law Journal, 23(1), pp. 29-50. HARRIS, J. (2004): On Cloning: Thinking in Action. London: Routledge.

HARRIS, J. (1990): Wrongful Birth. In: D. R. Bromham, M. E. Dalton \& J. C. Jackson (eds.): Philosophical Ethics in Reproductive Medicine. Manchester: Manchester University Press, pp. 156-170.

HUMAN ASSISTED REPRODUCTIVE TECHNOLOGY ACT NO 92 OF 2004, [online] [Retrieved February 2, 2018]. Available at: http://www.legislation.govt.nz/act/public/2004 /0092/latest/DLM319241.html.

HUMAN FERTILISATION AND EMBRYOLOGY ACT NO. 22 OF 2008, [online] [Retrieved February 2, 2018]. Available at: http://www.legislation.gov.uk/ukpga/2008/22/ contents.

HURSTHOUSE, R. (2013): Virtue Ethics. In: E. N. Zalta (ed.): The Stanford Encyclopedia of Philosophy (Fall 2013 Edition), [online] [Retrieved February 2, 2018]. Available at: http://plato.stanford.edu/archives/fall2013/entries/ethics-virtue.

LANCET EDITORIAL (1993): Too old to have a baby? In: Lancet, 34, pp. 1344-1345.

LANDAU, R. (2004): The promise of post-menopausal pregnancy. In: Social Work in Health Care, 41(1), pp. 53-69.

LARCHER, V. (2007): Ethical issues in respect of children born after assisted reproduction technologies. In: Archives of Disease in Childhood, 92(8), pp. 670-671.

LAW ON MEDICALLY ASSISTED REPRODUCTION AND THE DISPOSITION OF SUPERNUMERARY EMBRYOS AND GAMETES (2007): Act No. 6/7 of 2007.

LEE, R. G. \& MORGAN, D. (2001): Human Fertilisation and Embryology: Regulating the Reproductive Revolution. London: Blackstones Press.

LEE, E., MACVARISH, J., \& SHELDON, S. (2014): Assessing child welfare under the Human Fertilisation and Embryology Act 2008: a case study in medicalisation? In: Sociology of Health \& Illness, 36(4), pp. 500-515.

MARTIN, E. A. (2003): Oxford Dictionary of Law (7th ed.). Oxford: Oxford University Press. 
MC LANAHAN, S. \& SANDEFUR, G. (1996): Growing Up with a Single Parent: What Hurts, What Helps. Harvard: Harvard University Press.

MUMFORD, S. E., CORRIGAN, E. \& HULL, M. G. R. (1998): Access to assisted conception: a framework of regulation. In: Human Reproduction, 13(9), pp. 2349-2355.

PEARN, J. H. (1997): Gatekeeping and assisted reproductive technologies: the rights and responsibilities of doctors. In: Medical Journal of Australia, 167(6), pp. 318-320.

PENNINGS, G. (1995): Age and assisted reproduction. In: Medicine and Law, 14(7-8), pp. 531-41.

PENNINGS, G. (1999): The welfare of the child. In: Human Reproduction, 14(5), pp. 11461150.

PENNINGS, G. (2001): Postmenopausal women and the right of access to oocyte donation. In: Journal of Applied Philosophy, 18(2), pp. 174-175.

PENNINGS, G. (2011): Evaluating the welfare of the child in same-sex families. In: Human Reproduction, 26(7), pp. 1609-1615.

PENNINGS G., DE WERT, G., SHENFIELD, F., COHEN, J., DEVROEY, P. \& TARLATZIS, B. (2006): ESHRE Task Force on Ethics and Law 11: Posthumous assisted reproduction. In: Human Reproduction, 21(12), pp. 3050-3053.

PENNINGS, G., DE WERT, G., SHENFIELD, F., COHEN, J., TARLATZIS, B., \& DEVROPEY, P. (2007): ESHRE Task Force on Ethics and Law 13: The welfare of the child in medically assisted reproduction. In: Human Reproduction, 22(10), pp. 2585-2588.

PETERSON, M. (2005): Assisted reproductive technologies and equity of access Issues. In: Journal of Medical Ethics, 31(5), pp. 280-285.

RAUTAKALLIO-HOKKANEN, S. (2018): European Policy Audit on Fertility. Council of Europe meeting: "Access and diversity of medically assisted reproduction in Europe", Strasbourg, France, 22 - 23 February 2018.

SHELDON, S., LEE, E. \& MACVARISH, J. (2015): 'Supportive Parenting', Responsibility and Regulation: The Welfare Assessment under the Reformed Human Fertilisation and Embryology Act (1990). In: The Modern Law Review, 78(3), pp. 461-492.

SHENFIELD, F., PENNINGS, G., COHEN, J., DEVROEY, P, DE WERT, G. \& TARLATZIS, B. (2005): ESHRE Task Force on Ethics and Law 10: Surrogacy. In: Human Reproduction, 20(10), pp. 2705-2707.

SMAJDOR, A. (2015): Do women have a right to freeze their eggs? In: BioNews, 17(815), 17 August 2015.

SOBOTKA, T. (2010): Shifting Parenthood to Advanced Reproductive Ages: Trends, Causes and Consequences. In: J. C. Tremmel (ed.): A young generation under pressure? Heidelberg: Springer Verlag, pp. 129-154.

SOLBERG, B. (2008): Getting beyond the welfare of the child in assisted reproduction. In: Journal of Medical Ethics, 35(6), pp. 373-376.

SPRIGGS, M. \& CHARLES, T. (2003): Should HIV discordant couples have access to assisted reproductive technologies? In: Journal of Medical Ethics, 29(6), pp. 325-329.

STERN, J. E., CRAMER, C. P., GRFEEN, R. M., GARROD, A. \& DEVRIES, K. O. (2003): Determining access to assisted reproductive technology: reactions of clinic directors to ethically complex case scenarios. In: Human Reproduction, 18(6), pp. 1343-1352. STUHMCKE, A. (1997): Lesbian access to in vitro fertilisation. In: Australia Gay Lesbian Law Journal, 7(1997), pp. 15-40.

THE COUNCIL OF EUROPE (1989): Report on Human Artificial Procreation, [online] [Retrieved February 2, 2018]. Available at: https://rm.coe.int/16803113e4.

ZEILER, K. \& MALMQUIST, A. (2014): Lesbian shared biological motherhood: the ethics of IVF with reception of oocytes from partner. In: Medicine, Health Care and Philosophy, 17(3), pp. 347-355. 